\title{
Carbon-isotopic shifts associated with heterotrophy and biosynthetic pathways in direct- and indirect-developing sea urchins
}

\author{
Jennifer C. Villinski ${ }^{1,4}$, John M. Hayes ${ }^{3, *}$, Jeffrey T. Villinski ${ }^{2,5}$, \\ Simon C. Brassell ${ }^{1}$, Rudolf A. Raff ${ }^{2}$ \\ ${ }^{1}$ Biogeochemical Laboratories, Departments of Chemistry and of Geological Sciences, and ${ }^{2}$ Department of Biology, \\ Indiana University, Bloomington, Indiana 47405, USA \\ ${ }^{3}$ Department of Geology and Geophysics, Woods Hole Oceanographic Institution, Woods Hole, Massachussetts 02543, USA \\ ${ }^{4}$ Present address: North American Exploration, BP America, 501 Westlake Park Boulevard, Houston, Texas 77079, USA \\ ${ }^{5}$ Present address: Department of Biochemistry and Molecular Biology, Box 117, University of Texas, M D Anderson Cancer \\ Center, 1515 Holcombe Boulevard, Houston, Texas 77030, USA
}

\begin{abstract}
Natural abundances of ${ }^{13} \mathrm{C}$ were measured in bulk biomass and in individual lipids isolated from 2 species of sea urchins, Heliocidaris erythrogramma and H. tuberculata, and from calcareous and green benthic algae on which they were feeding. Planktonic larvae of $H$. erythrogramma are lecithotrophic whereas those of $H$. tuberculata are planktotrophic. The organisms were collected from a subtidal environment in Botany Bay, Sydney, Australia. The biomass of both consumers was enriched in ${ }^{13} \mathrm{C}$ relative to their diets by up to $1.8 \%$. The carbon skeletons of sterols from the urchins derive at least in part from de novo biosynthesis by the urchins. Depending on chain length and degree of unsaturation, carboxylic acids from the urchins derive from de novo biosynthesis $(14: 0$, unsaturated acids), from the diet (18:0), or from both these sources (16:0). H. tuberculata synthesizes a greater distribution and proportion of unsaturated carboxylic acids. Odd-C and branched-chain carboxylic acids derive in part from bacterial sources and are enriched in ${ }^{13} \mathrm{C}$ relative to algal lipids and depleted relative to those in urchins. Only $H$. erythrogramma, which uses wax esters as storage lipids in its relatively large and buoyant eggs, produces significant quantities of $n$-alkanols; $n$-alkanols in $H$. tuberculata derive from the diet. In terms of molecular distributions and isotopic compositions, the lipids in fecal matter from both heterotrophs resemble those of the diet rather than those of the urchins.
\end{abstract}

KEY WORDS: ${ }^{13} \mathrm{C} \cdot$ Heterotrophy $\cdot$ Isotope effect $\cdot$ Biosynthesis · Urchin · Sterol · Alcohol · Fatty acid

Resale or republication not permitted without written consent of the publisher

\section{INTRODUCTION}

Multiple studies have shown that the total biomass of consumers is enriched in ${ }^{13} \mathrm{C}$ relative to their diet (e.g. DeNiro \& Epstein 1978, Fry 1988, Michener \& Schell 1994). In aquatic communities, the magnitude is typically slightly more than 1\%o per trophic level (e.g. Yoshii et al. 1999, van der Zanden \& Rasmussen 2001), yet consumers often assimilate carbon skeletons entirely from their diet. Essential amino acids and unsaturated carboxylic acids provide the best-known examples. In such cases, whole molecules are built into the consumer's biomass and isotopic fractionation is not possible. Observed isotopic relationships between producers and consumers must therefore result from a competition between assimilation and other processes which are isotopically selective.

The diagram in Fig. 1 summarizes these possibilities. An autotrophic organism capable of synthesizing all its biochemical components is depicted as producing 


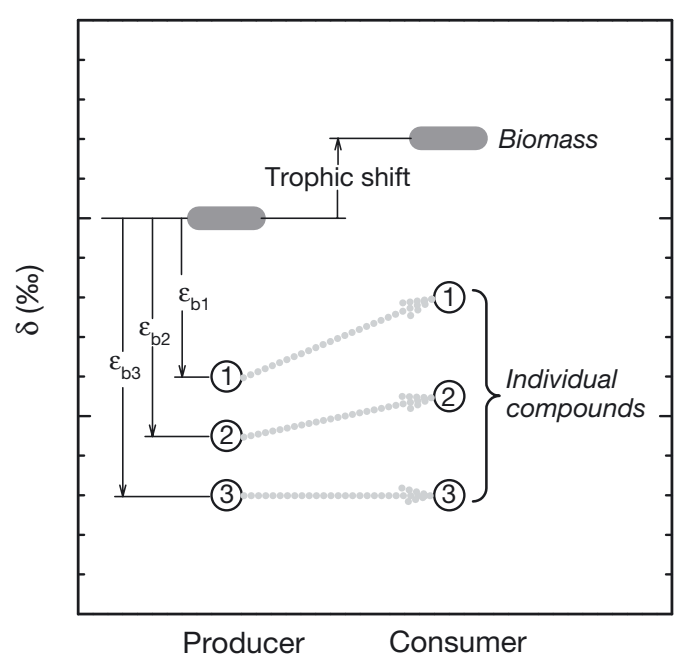

Fig. 1. Isotopic relationships between producers and consumers. Gray bars: total biomass; circled numbers: individual compounds present in both producer and consumer; $\varepsilon_{\mathrm{b}}$ terms: isotopic fractionations associated with biosyntheses of Components 1, 2, and 3 by producer; dashed arrows: relationships discussed in 'Introduction'. Same data presentation is used in Figs. 3, 4 \& 5

Compounds 1, 2, and 3. The related biosynthetic isotopic fractionations are $\varepsilon_{\mathrm{b} 1}, \varepsilon_{\mathrm{b} 2}$ and $\varepsilon_{\mathrm{b} 3}$. The same compounds are found in an animal which consumes that producer. The varying isotopic relationships indicated in the diagram yield information. Specifically, Compound 1 found in the consumer is definitely not assimilated directly from the producer. For this compound, the isotopic difference between the producer and the consumer is equal to the trophic shift, suggesting that all of the consumer's Compound 1 was synthesized de novo. Conversely, it is probable that all of the consumer's Compound 3 was assimilated from the producer. Compound 2 is an intermediate case, wherein the consumer's supply probably derives from both assimilation and de novo biosynthesis. Alternative interpretations cannot be excluded unless specific values of $\varepsilon_{\mathrm{b}}$ are known. In the case of Compound 2, for example, it is possible that $\varepsilon_{\mathrm{b} 2}$ is greater in the consumer than in the producer.

This report uses isotopic signals of this kind to compare flows of carbon in 2 species of sea urchins, both members of the genus Heliocidaris. We examined 3 classes of compounds: sterols, $n$-alkanols, and $n$-alkanoic acids. The selected genus has been studied extensively because dramatically different developmental modes have evolved within it (Raff 1992, Lawrence \& Byrne 1994, Tsushima et al. 1995, Emlet \& HoeghGuldberg 1997, Hoegh-Guldberg \& Emlet 1997). Developing embryos of $H$. tuberculata go through a feeding, larval phase that is common to most echinoids.
However, the evolutionarily derived embryos of $H$. erythrogramma develop directly and do not have a feeding larval stage. The eggs of $H$. erythrogramma are large, lipid-rich, and float. The compositions and abundances of storage lipids utilized by these species have been studied with regard to maternal provisioning strategies (Villinski et al. 2002). H. erythrogramma stores wax esters in the gonad and eggs, whereas the dominant lipids of $H$. tuberculata are triglycerides. These storage strategies appear to be linked to the developmental modes mentioned above. This study is the first to characterize these lipid distributions with respect to their isotopic compositions and to compare them with those of food sources and excreted materials.

This report bears also on the impacts of heterotrophy on carbon isotopic records in sediments. It follows earlier studies in which the molecular distributions (e.g. Volkman et al. 1980, Prahl et al. 1984, Bradshaw et al. 1989) and the isotopic compositions (e.g. Des Marais et al. 1980, Stott et al. 1997, Grice et al. 1998, Pancost et al. 1999) of individual compounds have been followed through trophic steps. Most marine organic matter deposited and preserved in sediments has been reworked by bacteria, fungi, or zooplankton (Wakeham 1995), such that the associated isotopic fractionations must be thoroughly understood if carbon-isotopic signals are to be interpreted correctly.

\section{MATERIALS AND METHODS}

Sample collection. Sea urchins and benthic algae were collected in December 1998 and January 1999 off the north coast of Bare Island in Botany Bay, south of Sydney, Australia. This temperate to subtropical habitat ranges from 2 to $6 \mathrm{~m}$ in depth in the subtidal region. Large beds of calcareous and green macroalgae were present and, based on gut contents and available food sources, appear to comprise the primary food source for both sea urchin species. Echinoids are mainly omnivorous detritivores, but feed on anything in their path, including living macroalgae and any associated symbionts. Accordingly, the macroalgae here probably provide the major food source, but not the only food source. Observations of gut contents suggest that Heliocidaris erythrogramma prefers the green alga and that $H$. tuberculata prefers the calcareous species, but this observation is not definitive, and it is more likely that both species consume both algal types.

Macroalgae of each type were collected with the sea urchins and extracted without separation into component parts (e.g. holdfast and stems). Accordingly, isotopic compositions represent the entire plant. The isotopic composition of the macroalgae may vary seasonally. If so, the present sampling may not represent 
the full range of dietary compositions. Also, urchin biomass may turn over slowly. Consequently, the compositions determined may reflect food sources consumed over more than 1 season.

Female sea urchins were dissected and divided into 2 parts, gut and gonad, which constitute the main portions of their biomass. Gut tissue includes the esophagus and intestines, but excludes any contents of those organs. Fecal pellets present in the lower portion of the gut were collected separately. The timing of the collection meant that the upper guts were largely empty, given the preference of the sea urchins for nocturnal feeding. The overall composition of the biomass in the 2 species is similar, except for their gonads (Lawrence \& Byrne 1994). In the gonads of female Heliocidaris erythrogramma, approximately $8 \%$ of the organic biomass is carbohydrate, $52 \%$ is lipid, and $40 \%$ is protein; in $H$. tuberculata it is $13 \%$ carbohydrate, $29 \%$ lipid, and $58 \%$ protein. The biomass composition of gut portions of these species had not previously been examined.

Both urchin biomass and algal samples were stored frozen at $-80^{\circ} \mathrm{C}$ immediately after dissection, and were transported on dry ice to Indiana University, where they were stored at $-20^{\circ} \mathrm{C}$ until mailing, on dry ice, to Woods Hole for extraction. This study focuses on saponifiable lipids to obviate any effects from thawing during transport or storage, including potential breakdown of complex lipids.

Extraction and separation. The analytical procedures used for extraction and separations are summarized in Fig. 2. Lipids were extracted with 99:1 dichloromethane:methanol at $100^{\circ} \mathrm{C}$ using a Dionex accelerated solvent extraction (ASE) system at Woods Hole Oceanographic Institution. This high-pressure system occasionally mobilized non-lipid biomass or salts. Extracts were therefore filtered through GF/F filters and lipids were purified using Bligh \& Dyer (1959) separation (Fig. 2).

The resulting total lipid extracts (TLEs) were divided into 2 parts. One half was saponified with $0.5 \mathrm{M} \mathrm{KOH}$ in methanol at $90^{\circ} \mathrm{C}$ for $2 \mathrm{~h}$. Products of saponification were then separated into 4 fractions via solid-phase extraction using $3 \mathrm{ml}$, Varian aminopropyl Bond-Elut cartridges. The volumes and types of solvents used to elute each fraction are listed in Fig. 2. These fractions comprised (1) hydrocarbons, (2) ketones, (3) n-alkanols and sterols, and (4) carboxylic acids. This procedure provided a quick and thorough assessment of the main components of the lipids but not of the distribution of carboxylic acid types among the complex lipids. Thin-layer chromatography (TLC) was used to separate the second half of the extract into polar and nonpolar lipids (wax esters and triglycerides) to assess the amount of storage lipids present and to provide more specific analyses of acids and/or $n$-alkanols within specific lipid classes. Up to $10 \mathrm{mg}$ of sample was loaded onto a plate and eluted with an 80:20:1 mixture of petroleum ether, ethyl ether, and glacial acetic acid. Depending on fluctuations in laboratory

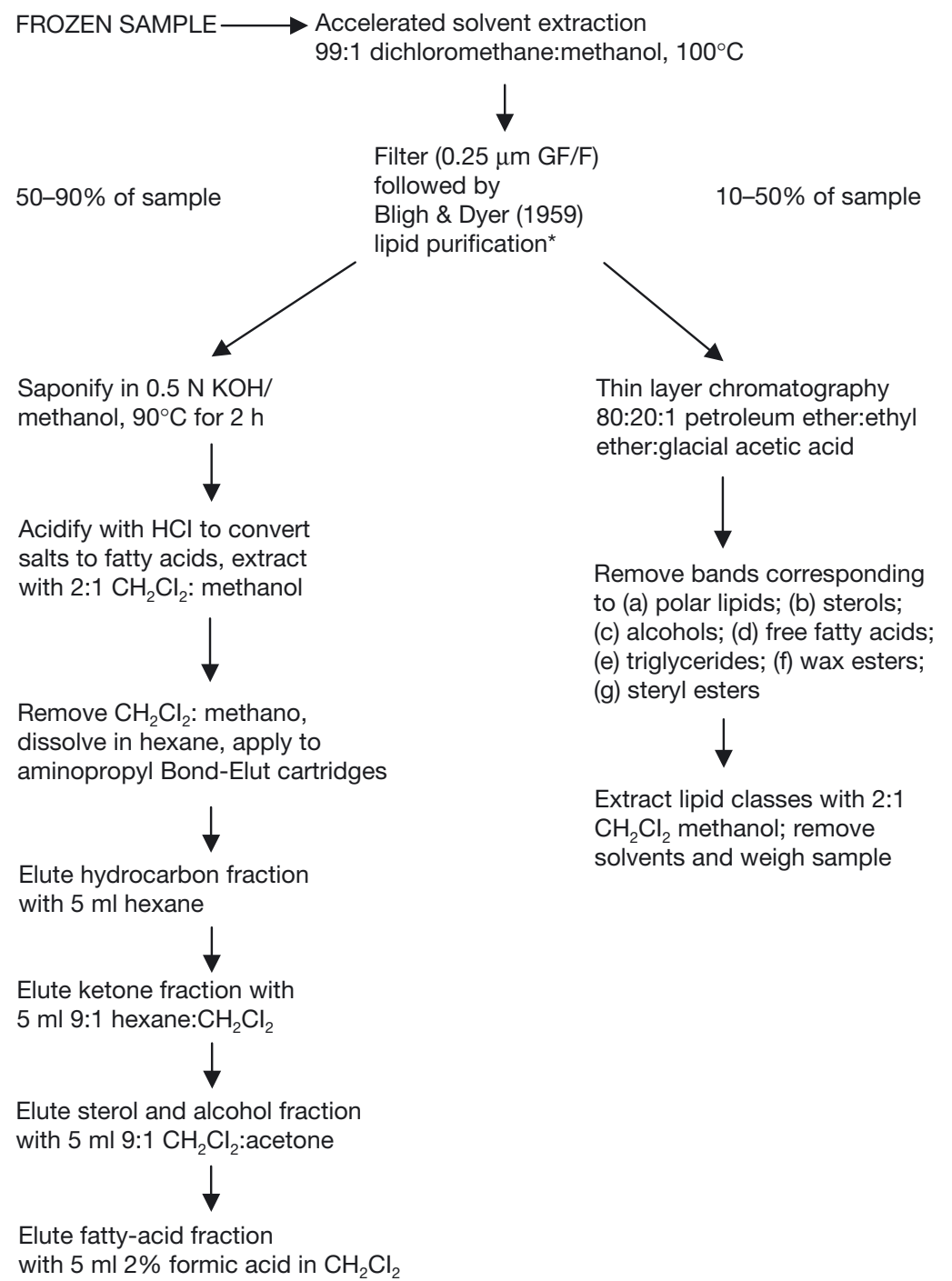

*Extraction with 2:1 methanol:chloroform followed by addition of water and removal of the methanol-water phase

Fig. 2. Analytical flowchart showing extraction and separation methods 
humidity, this mixture was occasionally altered to 85:15:1 to improve separation. Bands corresponding to sterols, free $n$-alkanols, free carboxylic acids, triglycerides, and wax esters were identified by use of standards, then scraped from the plates and extracted from the silica gel via sonication in 2:1 dichloromethane:methanol followed by filtration through a GF/F filter. In all cases, weights were obtained by drying under a stream of $\mathrm{N}_{2}$ gas.

Identification and quantitation of biomarkers. All fractions were analyzed using a Hewlett-Packard 6980 GC-FID (gas chromatograph-flame-ionization detector) and compounds were identified from mass spectra obtained with a Finnigan TSQ 700. The column used in all instruments was a 60-m Restek RTX-1 (100\% dimethyl polysiloxane), with $0.32 \mathrm{~mm}$ inner diameter and $0.5 \mu \mathrm{m}$ film thickness. The column temperature was programmed from 60 to $320^{\circ} \mathrm{C}$ at $4^{\circ} \mathrm{min}^{-1}$, then held at $320^{\circ}$ for $60 \mathrm{~min}$ for the sterol and alcohol fractions, or for $25 \mathrm{~min}$ for carboxylic acid fractions. The FID was calibrated regularly by injection of $n$-alkane standards. For non-hydrocarbons, these values were corrected for the carbon contributed by trimethylsilyl or methyl derivatives.

Identifications of compounds were based on comparisons to retention times and mass spectra of standards and, where standards were not available, by reference to retention indices and spectra reported previously. Sterols were identified using retention indices (Patterson 1971, Itoh et al. 1982, Smith 1984) based on 2 sterols, cholesterol $\left(27 \Delta^{5}\right)$ and $\beta$-sitosterol $\left(29 \Delta^{5}\right)$. These techniques provided straightforward identifications for all compounds except 2 pairs of mono- and diunsaturated $\mathrm{C}_{18}$ carboxylic acids and a steroidal diol. Information on these components is provided in 'Results and discussion'.

Isotopic analyses. Carbon isotopic composition and elemental composition of bulk biomass were determined at Stanford University using a Carlo Erba NA1500 Series II coupled to a Finnigan Delta Plus mass spectrometer. Biomass samples were cleaned with deionized water, freeze-dried, and homogenized by grinding prior to analysis.

Carbon isotopic compositions of individual compounds were determined by isotope-ratio-monitoring gas chromatography-mass spectrometry (irmGCMS; Hayes et al. 1989). Compounds separated using a HP5890 GC were combusted and oxidized to $\mathrm{CO}_{2}$ using a continuous-flow combustion interface. The $\mathrm{CO}_{2}$, after passing through a Nafion dryer to remove water (Leckrone \& Hayes 1997), was introduced into a Finnigan MAT252 mass spectrometer for continuous measurement of specific mass to charge ratios $(\mathrm{m} / \mathrm{z})$ of 44, 45, and 46. Both external and internal standards were used to calibrate the instrument: deuterated $n$-alkane standards of known isotopic composition were co-injected with each sample, and peaks of $\mathrm{CO}_{2}$ gas with a known isotopic composition were analyzed before and after each run. Injections of $n$-alkanes and deuterated $n$-alkanes at the beginning of each day were used to calibrate the instrument and determine standard deviations. Deviations of $0.2 \%$ or less were tolerated in these standards. Measurements of carbon isotope ratios for sterols, alkanols, and carboxylic acids were corrected for the isotopic compositions of derivatizing agents by comparison with derivatized standards of known isotopic composition. Based on all replicates, the pooled standard deviation for a single analysis was $0.7 \%$.

\section{RESULTS AND DISCUSSION}

\section{Bulk analyses}

Relative abundances of the major lipid classes in each sample are summarized in Table 1.

Urchin biomass. Gonadal lipids differed significantly between the females of the 2 species. In Heliocidaris erythrogramma, polar lipids (i.e. phospholipids) and wax esters were dominant and accounted for $65 \%$ of the total lipid extract. In $H$. tuberculata, triglycerides were dominant, followed by polar lipids and free carboxylic acids. Wax esters were only trace constituents. Consequently, free $n$-alkanols were proportionally more abundant in $H$. erythrogramma, and concentrations of free carboxylic acids were markedly higher in H. tuberculata.

In both species, polar compounds (polar lipids, sterols, free $n$-alkanols, and free carboxylic acids) dominated lipids from gut tissues. Significant amounts of free carboxylic acids were found in Heliocidaris erythrogramma, presumably because the gut is a site for both synthesis and catabolism of organic matter. In contrast, sterols and steryl esters were more abundant in $H$. tuberculata. Neither wax esters nor triglycerides comprised a significant portion of the gut-tissue lipids in either species.

Fecal matter from both species contained significant amounts of wax esters or triglycerides as well as polar compounds. In Heliocidaris erythrogramma, in which gonadal wax esters are abundant, triglycerides were rare in the fecal matter while wax esters comprised $23 \%$ of the lipid extract. In H. tuberculata, in which gonadal wax esters are rare, triglycerides made up $31 \%$ of the lipids in fecal matter.

Benthic algae. Polar lipids overwhelmingly dominated the algal lipids $(74 \%)$ in both the green and calcareous species. Unlike the extracts of urchin gonads, the algal extracts contained only minor $(<6 \%)$ propor- 
Table 1. Heliocidaris spp. grazing on benthic algae. Relative abundance (\%) of lipid classes

\begin{tabular}{|c|c|c|c|c|c|c|c|}
\hline Sample & Polar lipids & Sterols & $\begin{array}{c}\text { Free } \\
n \text {-alkanols }\end{array}$ & $\begin{array}{c}\text { Free } \\
\text { carboxylic } \\
\text { acids }\end{array}$ & $\begin{array}{l}\text { Trigly- } \\
\text { cerides }\end{array}$ & $\begin{array}{l}\text { Wax } \\
\text { esters }\end{array}$ & $\begin{array}{l}\text { Steryl } \\
\text { esters }\end{array}$ \\
\hline \multicolumn{8}{|l|}{ Benthic algae } \\
\hline Calcareous & 74 & 3.0 & 13 & 2.0 & 2.4 & 2.8 & 2.5 \\
\hline Green & 74 & 6.5 & 6.8 & 6.2 & 2.0 & 1.1 & 3.4 \\
\hline \multicolumn{8}{|l|}{ H. tuberculata } \\
\hline Gut & 44 & 18 & 8.0 & 8.7 & 5.9 & 4.1 & 11 \\
\hline Gonad & 20 & 11 & 6.6 & 16 & 29 & 7.0 & 10 \\
\hline Fecal pellets & 17 & 8.4 & 8.1 & 12 & 31 & 11 & 12 \\
\hline \multicolumn{8}{|c|}{ H. erythrogramma } \\
\hline Gut & 34 & 2.6 & 3.0 & 42 & 9.3 & 3.6 & 5.6 \\
\hline Gonad & 31 & 8.0 & 7.8 & 6.9 & 8.7 & 35 & 2.5 \\
\hline Fecal pellets & 12 & 14 & 13 & 17 & 8.6 & 23 & 13 \\
\hline
\end{tabular}

Table 2. Summary of sterol names and structures

\begin{tabular}{|c|c|c|c|c|}
\hline Abbreviation & IUPAC name & Common name & Retention index & Source \\
\hline $26 \Delta^{5,22}$ & 24-norcholesta-5, 22E-dien-3 $\beta$-ol & & 0.50 & Patterson (1971) \\
\hline $27 \Delta^{5, x}$ & Probable $\mathrm{C}_{27}$ dienol with $\Delta^{5}$ unsaturation & & 0.87 & This study \\
\hline $27 \Delta^{22}$ & $5 \alpha$-cholest-22E-en-3 $\beta$-ol & & 0.90 & Smith (1984) \\
\hline $27 \Delta^{5}$ & Cholest-5-en-3 $\beta$-ol & Cholesterol & 1.00 & Smith (1984) \\
\hline $27 \Delta^{0}$ & $5 \alpha$-cholestan- $3 \beta$-ol & Cholestanol & 1.03 & Smith (1984) \\
\hline $28 \Delta^{22}$ & 24 -methyl- $5 \alpha$-cholest-22E-en-3 $\beta$-ol & Brassicastanol & 1.15 & Smith (1984) \\
\hline $28 \Delta^{5,24(28)}$ & 24-methylcholesta-5, 24(28)-dien-3ß-ol & & 1.28 & Patterson (1971) \\
\hline $29 \Delta^{5}$ & 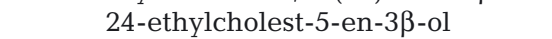 & $\beta$-sitosterol & 1.63 & Smith (1984) \\
\hline $29 \Delta^{5,24(28)}$ & 24-ethylcholesta-5, 24(28)-dien-3 $\beta$-ol & Fucosterol & 1.63 & Patterson (1971) \\
\hline
\end{tabular}

tions of triglycerides and wax esters. The remaining classes were present in similar abundance, except for $n$-alkanols in the calcareous species, which comprised $\sim 13 \%$ of the lipid.

Isotopic compositions. Values of $\delta^{13} \mathrm{C}$ for total biomass were $-14.6 \pm 0.8 \%$ for Heliocidaris erythrogramma and $-16.1 \pm 1.2 \%$ o for $H$. tuberculata (mean $\pm \mathrm{SD}, 3$ individuals of each species, all collected at the same time and location). The $\delta^{13} \mathrm{C}$ value of algal biomass for the green benthic alga was $-16.3 \pm 0.1 \%$, whereas that of the calcareous species was $-17.5 \pm$ $0.2 \%$. Overall, the heterotrophs were enriched in ${ }^{13} \mathrm{C}$ relative to their diet by 1.4 to $1.7 \%$.

\section{Sterols}

Molecular composition. Cholesterol served as a retention standard. Other sterols (henceforth designated by the abbreviations listed in Table 2) were identified from their relative retention times and mass spectra (pertinent literature references are cited in Table 2). The identity of 1 sterol (the second entry in Table 2) could not be verified. Its retention characteristics and a mass spectrum with an apparent molecular ion at a $\mathrm{m} / \mathrm{z}$ of 456 were consistent with a $\mathrm{C}_{27}$ dienol with $\Delta^{5}$ unsaturation. The second double bond could not be placed precisely and might be in the side chain (hence the abbreviation $27 \Delta^{5, x}$ ). Alternatively, the presence of an ion at $546 \mathrm{~m} / \mathrm{z}$ raises the possibility that this component was a $\mathrm{C}_{27} \Delta^{5}$ diol, with an $\mathrm{OH}$ at $\mathrm{C}-3$ and, based on the relative sizes of the $255 \mathrm{~m} / \mathrm{z}$ and $327 \mathrm{~m} / \mathrm{z}$ fragment ions in comparison with those of $5 \alpha-\mathrm{OH}$ cholesterol (Bortolomeazzi et al. 1999), a second $\mathrm{OH}$ group in the side chain.

As shown in Table 3, cholesterol was the major sterol in most of the samples of urchin tissue. The fecal pellets from both species contained low concentrations of sterols. Those from Heliocidaris erythrogramma were almost $80 \%$ cholesterol, while those from $H$. tuberculata were dominated by $27 \Delta^{5, x}$. The green alga yielded cholesterol and traces of steryl diols. The calcareous alga yielded appreciable amounts of cholestanol and a few minor components in addition to cholesterol. Notably, 28 $\Delta^{22}$ was found in the calcareous algae and fecal pellets but not in the urchin tissues.

Isotopic compositions. Values of $\delta$ for individual sterols are summarized in Table 4 (note: the values reported for urchin biomass pertain to the specific individuals that yielded the lipid extracts and thus differ from the averages cited above). In Fig. 3, 2 sets of comparisons are depicted graphically: (1) isotopic relation- 
Table 3. Heliocidaris spp. grazing on benthic algae. Relative abundance (\%) of individual sterols. tr: trace

\begin{tabular}{|c|c|c|c|c|c|c|c|c|c|}
\hline \multirow[b]{2}{*}{ Index } & \multirow[b]{2}{*}{ Sterol } & \multicolumn{2}{|c|}{ Algae } & \multicolumn{3}{|c|}{ H. tuberculata } & \multicolumn{3}{|c|}{ H. erythrogramma } \\
\hline & & Calcareous & Green & Gut & Gonad & Feces & Gut & Gonad & Feces \\
\hline 1 & $26 \Delta^{5,22}$ & & & & & & & 0.6 & \\
\hline 2 & $27 \Delta^{5, x}$ & 9.7 & & & & 59 & & 16 & \\
\hline 3 & $27 \Delta^{22}$ & 7.1 & & & & & & & \\
\hline 4 & $27 \Delta^{5}$ & 22 & $\sim 100$ & 91 & 93 & 41 & 91 & 80 & 78 \\
\hline 5 & $27 \Delta^{0}$ & 50 & & & & & 9.5 & & 14 \\
\hline 6 & $28 \Delta^{22}$ & 11 & & & & & & & $\operatorname{tr}$ \\
\hline 7 & $28 \Delta^{5,24(28)}$ & & & 3.0 & 3.6 & & & 2.1 & 8.0 \\
\hline 8 & $29 \Delta^{5}$ & & & & & & & 2.3 & \\
\hline 9 & $29 \Delta^{5,24(28)}$ & & & 6.0 & 3.1 & & & & \\
\hline
\end{tabular}

Table 4. Heliocidaris spp. grazing on benthic algae. Isotopic composition (\%) of bulk samples (biomass) and sterols, $\delta^{13} \mathrm{C}$ versus VPDB. Values reported for urchin biomass pertain to specific individuals that yielded the lipid extracts, and thus differ from averages cited in text

\begin{tabular}{|c|c|c|c|c|c|c|c|c|c|c|}
\hline \multirow[b]{4}{*}{ Index } & \multirow[b]{4}{*}{ Sterol } & \multirow{4}{*}{ Biomass: } & \multicolumn{2}{|c|}{ Algae } & \multicolumn{3}{|c|}{ H. tuberculata } & \multicolumn{3}{|c|}{ H. erythrogramma } \\
\hline & & & Calcareous & Green & & & & & & \\
\hline & & & -17.5 & -16.3 & & -16.0 & & & -13.8 & \\
\hline & & & & & Gut & Gonad & Feces & Gut & Gonad & Feces \\
\hline 1 & $26 \Delta^{5,22}$ & & & & & & & & -24.2 & \\
\hline 2 & $27 \Delta^{5, x}$ & & -23.9 & & & & -23.0 & & -23.9 & \\
\hline 3 & $27 \Delta^{22}$ & & -25.2 & & & & & & & \\
\hline 4 & $27 \Delta^{5}$ & & -21.1 & -20.8 & -21.7 & -23.9 & -19.6 & -18.9 & -19.9 & -20.3 \\
\hline 5 & $27 \Delta^{0}$ & & -22.4 & & & & & -22.8 & & -22.2 \\
\hline 6 & $28 \Delta^{22}$ & & -25.1 & & & & & & & \\
\hline 7 & $28 \Delta^{5,24(28)}$ & & & & & & & & -23.2 & \\
\hline 8 & $29 \Delta^{5}$ & & & & & & & & -22.6 & \\
\hline
\end{tabular}

ships between the same or similar compounds in producers and consumers (algae vs urchins); (2) isotopic relationships between sterols and the biomass of the organism in which they were found. The first comparison examines trophic effects; the second reflects biosynthetic fractionations and, in consumers, the assimilation of carbon skeletons from the diet. The horizontal grid lines indicate depletions of ${ }^{13} \mathrm{C}$ in sterols relative to biomass in each organism.

The depletion of ${ }^{13} \mathrm{C}$ in algal $27 \Delta^{5}$ and $27 \Delta^{0}$ relative to biomass was on the order of $4.5 \%$, which is in the middle of the range of values observed for algal cultures (Hayes 2001). The larger depletion observed for 2 lowabundance sterols in the calcareous alga (see Table 4) is not unprecedented, but interesting in that it differed significantly from that in $27 \Delta^{5}$ and $27 \Delta^{0}$. If all these sterols were indeed from the same organism (difficult to guarantee in these field-collected samples), it probably indicates that the compounds were synthesized at different times.

In Fig. 3, 2 trends appear, specifically an enrichment of ${ }^{13} \mathrm{C}$ in the biomass of the consumers relative to that of the producers (about $2 \%$ assuming that Heliocidaris tuberculata and $H$. erythrogramma feed mainly on the calcareous and the green alga, respectively) and a less pronounced enrichment of ${ }^{13} \mathrm{C}$ in the sterols extracted from the consumers. If the urchins obtained all their sterols by assimilating carbon skeletons provided by the diet, the $\delta$ values of the sterols would describe a flat line on this graph. If, in contrast, all the animal sterols were synthesized de novo, their $\delta$ values would trend upward as strongly as those of the biomass. The observed slopes are intermediate, and must reflect a combination of assimilated and urchin-produced sterols. This is consistent with previous findings that showed incorporation of dietary sterols in other marine invertebrates (Voogt et al. 1993, Soudant et al. 1996, Veron et al. 1996). The $27 \Delta^{5}$ from the gonad of $H$. tuberculata is an outlier. The divergence must reflect either a specific biosynthetic system or an isotopically depleted diet at some point in the organism's past (i.e. during production of the gonadal tissue).

The calcareous tests or exoskeletons of the urchins were not examined. In earlier work, CoBabe \& Ptak (1999) found that the composition of sterols in the test of the urchin Strongylocentrotus sp. was similar to that in its diet, but that they comprised only a small percentage of the total lipid in the urchin. 


\section{n-Alkanols}

Molecular distribution. n-Alkanols (Table 5) comprised a significant portion of the products of saponification of the total lipid fractions for samples from Heliocidaris erythrogramma, the same species in which wax esters appear prominently in female gonadal and gut tissues. The distributions with respect to carbon number in those tissues were similar but not congruent. $n$-Alkanols in both the gonad and gut were dominated by $\mathrm{C}_{16}, \mathrm{C}_{17}$, and $\mathrm{C}_{18}$ components. The gut also contained significant percentages of $C_{12}$ and $C_{14}$ homologues.

A significant portion of the gonadal lipids is associated with the eggs produced by these urchins. These have been extensively studied in terms of maternal provisioning and developmental strategies (e.g. Raff 1992, Hoegh-Guldberg \& Emlet 1997). The distributions of $n$-alkanols found in analyses of lipids from the eggs (Villinski et al. 2002) are reported here for comparison.

$n$-Alkanols were not detected in the gonad from Heliocidaris tuberculata, either in the saponified totallipid extract or the free-alcohol fraction. Eggs from this species contained minimal amounts of wax esters (3.5 wt\%; Villinski et al. 2002). Accordingly, traces of $n$-Alkanols (below detection limits) must have been present in the gonad extract. Interestingly, the distribution in the wax esters from $H$. tuberculata eggs is quite different from that found in either the gut or fecal pellets of the urchin. The alcohol fraction derived from the saponification of the lipids extracted from the gut of $H$. tuberculata was dominated by $n$-tetradecanol.

Distributions of $n$-alkanols in fecal pellets from both Heliocidaris erythrogramma and $H$. tuberculata were

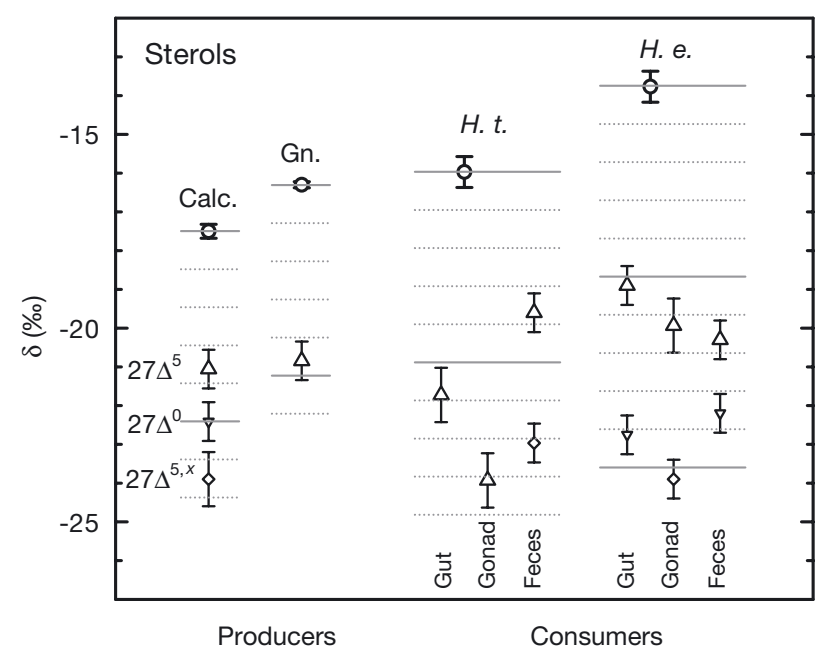

Fig. 3. Heliocidaris tuberculata ( $H$. t.) and $H$. erythrogramma (H. e.) grazing on benthic algae. Isotopic compositions of sterols. Calc., Gn.: calcareous and green algae eaten by sea urchins. Field observations suggested that $H$. tuberculata prefers calcareous alga whereas $H$. erythrogramma mainly consumes green alga. Left-to-right arrangement has significance only in that it separates producers and consumers. $(\Delta, \nabla, \diamond) \delta$ values for $27 \Delta^{5}, 27 \Delta^{0}$ and $27 \Delta^{5, x}$, respectively. For each organism, depletion of ${ }^{13} \mathrm{C}$ in individual sterols relative to biomass is indicated by horizontal grid lines superposed on graph; e.g. for $27 \Delta^{5}$ in green alga, depletion amounts to approximately $4.7 \%$. Error bars here and in subsequent graphs are \pm SE of mean $(0.7 / \sqrt{n}$, where $0.7 \%$ is standard deviation of a single analysis and $\mathrm{n}$ is number of replicate analyses)

dominated by the $\mathrm{C}_{16}$ compound even though $\mathrm{C}_{18}$ is more abundant in the tissues. Distributions of $n$-alkanols in the algae are also dominated by $n \mathrm{C}_{18}$. Accordingly, there is no readily apparent source for the abundant $n$-hexadecanol in the fecal pellets. Isotopic evidence bearing on this question is discussed below.

Table 5. Heliocidaris spp. grazing on benthic algae. Relative abundance (\%) of individual $n$-alkanols. Alcohols were not detected in gonad of $H$. tuberculata

\begin{tabular}{|c|c|c|c|c|c|c|c|c|c|}
\hline \multirow[b]{2}{*}{ n-Alkanols } & \multicolumn{2}{|c|}{ Algae } & \multicolumn{3}{|c|}{ H. tuberculata } & \multicolumn{4}{|c|}{ H. erythrogramma } \\
\hline & Calcareous & Green & Gut & $\operatorname{Eggs}^{a}$ & Feces & Gut & Gonad & $\operatorname{Eggs}^{\mathrm{a}}$ & Feces \\
\hline $\mathrm{C}_{12}$ & & & 14 & 8.6 & & 27 & 3.5 & & \\
\hline $\mathrm{C}_{13}$ & & & & & & & 2.4 & & \\
\hline $\mathrm{C}_{14}$ & & & 46 & 6.2 & 3.3 & 11 & 5.8 & 1.7 & 4.2 \\
\hline $\mathrm{C}_{15}$ & & & & & 2.0 & 3.1 & 5.8 & 2.2 & 1.4 \\
\hline $\mathrm{C}_{16}$ & 16 & 3.6 & 15 & 11 & 81 & 14 & 25 & 18 & 69 \\
\hline $\mathrm{C}_{17}$ & & & 6.9 & & 5.4 & 14 & 21 & 2.3 & 1.9 \\
\hline $\mathrm{C}_{18}$ & 61 & 96 & 19 & 49 & 8.5 & 31 & 37 & 75 & 3.5 \\
\hline $\mathrm{C}_{19}$ & & & & 5.7 & & & & & \\
\hline $\mathrm{C}_{20}$ & & & & 18 & & & & & 2.4 \\
\hline $\mathrm{C}_{22}$ & & & & & & & & & 4.4 \\
\hline $\mathrm{C}_{24}$ & & & & & & & & & 3.8 \\
\hline $\mathrm{C}_{26}$ & & & & & & & & & 1.7 \\
\hline $\mathrm{C}_{30}$ & 23 & & & & & & & & 4.7 \\
\hline $\mathrm{C}_{32}$ & & & & & & & & & 2.8 \\
\hline${ }^{\mathrm{a} D a t a}$ from & aski et al. (2 & & & & & & & & \\
\hline
\end{tabular}


Table 6. Heliocidaris spp. grazing on benthic algae. Isotopic composition (\%) of bulk samples (biomass) and $n$-alkanols, $\delta^{13} \mathrm{C}$ versus VPDB. Alcohols were not detected in gonad of H. tuberculata

\begin{tabular}{|c|c|c|c|c|c|c|c|c|}
\hline \multirow[b]{4}{*}{$n$-Alkanols } & \multirow{4}{*}{ Biomass: } & \multicolumn{2}{|c|}{ Algae } & \multicolumn{2}{|c|}{ H. tuberculata } & \multicolumn{3}{|c|}{ H. erythrogramma } \\
\hline & & Calcareous & Green & & & & & \\
\hline & & -17.5 & -16.3 & & & & -13.8 & \\
\hline & & & & Gut & Feces & Gut & Gonad & Feces \\
\hline $\mathrm{C}_{12}$ & & & & & & -29.7 & -23.1 & \\
\hline $\mathrm{C}_{14}$ & & -19.9 & & & -22.8 & -23.8 & & -26.2 \\
\hline $\mathrm{C}_{15}$ & & & & & -21.0 & -16.4 & -18.2 & -24.9 \\
\hline $\mathrm{C}_{16}$ & & -21.5 & -23.4 & -21.3 & -25.0 & -19.2 & -18.7 & -25.5 \\
\hline $\mathrm{C}_{17}$ & & & & & -16.3 & -17.6 & -16.9 & -28.9 \\
\hline $\mathrm{C}_{18}$ & & -26.8 & -29.6 & -29.1 & -22.5 & -19.8 & -18.0 & -26.1 \\
\hline $\mathrm{C}_{20}$ & & & & & & & & -24.9 \\
\hline $\mathrm{C}_{22}$ & & & & & & & & -29.8 \\
\hline $\mathrm{C}_{24}$ & & & & & & & & -28.5 \\
\hline $\mathrm{C}_{26}$ & & & & & & & & -28.9 \\
\hline $\mathrm{C}_{30}$ & & & & & & & & -26.8 \\
\hline
\end{tabular}

Isotopic compositions. ${ }^{13} \mathrm{C}$ was most strongly enriched in the $\mathrm{C}_{16}$ and $\mathrm{C}_{18} n$-alkanols extracted from tissues of Heliocidaris erythrogramma (Table 6, Fig. 4). Relative to the algal food sources, the difference was 2 to $5 \%$ or $\mathrm{C}_{16}$ and 7 to $11 \%$ o for the more abundant $\mathrm{C}_{18}$. Together with the relatively high abundance and the associated use of wax esters as storage lipids in eggs (Villinski et al. 2002), these isotopic offsets indicate that these compounds are mainly products of de novo synthesis in $H$. erythrogramma. Crustaceans, in particular copepods, have been reported to make their own $n$-alkanols and to combine them with dietary carboxylic acids during synthesis of wax esters (Corner 1986). The present results suggest that echinoids that use wax esters as storage lipids may also synthesize their $n$-alkanols de novo rather than collecting them from the food source.

Significant concentrations of the $\mathrm{C}_{15}$ and $\mathrm{C}_{17}$ $n$-alkanols were also found in Heliocidaris erythrogramma (Table 5). As shown in Table 6, they were enriched in ${ }^{13} \mathrm{C}$ even more strongly than the even-C alcohols and could not have an algal source. For biosynthetic reasons, 4 carbon atoms in the $\mathrm{C}_{15^{-}}$and $\mathrm{C}_{17}$ alkanols have $\delta$ values potentially different from those at analogous positions in the $\mathrm{C}_{14}$ - and $\mathrm{C}_{16}$ homologues; 3 of these carbon atoms are at the methyl terminal of the odd-C product, where a $\mathrm{C}_{3}$ starter group occupies positions deriving from acetyl-CoA in even- $\mathrm{C}$ products; the fourth is at the hydroxyl terminal, where specific isotopic fractionations may have affected the odd-C product. If the odd-C products are enriched by $2 \%$, the 4 distinct carbon positions must be enriched relative to the rest of the carbon skeleton by $8.5 \%$. This offset is implausibly large, indicating that the oddand even-C alcohols must be synthesized from different pools of acetyl-CoA (i.e. at different times or in different cells).
As noted earlier, fecal pellets from Heliocidaris erythrogramma yielded a different mixture of $n$-alkanols. The isotopic results (Table 6, Fig. 4) now show that these excreted products were depleted in ${ }^{13} \mathrm{C}$ by $6 \%$ relative to the $n$-alkanols in the urchin's tissues. Accordingly, they cannot represent leakage of those de novo-biosynthesized products. Fecal pellets from $H$. tuberculata also contained a mixture of $n$-alkanols dominated by $\mathrm{C}_{18}$. The $\mathrm{C}_{16}$ alcohols in the fecal pellets were depleted in ${ }^{13} \mathrm{C}$ relative to those in the algae. In the case of $H$. erythrogramma and the green alga, the depletion was barely significant, but it mirrors the

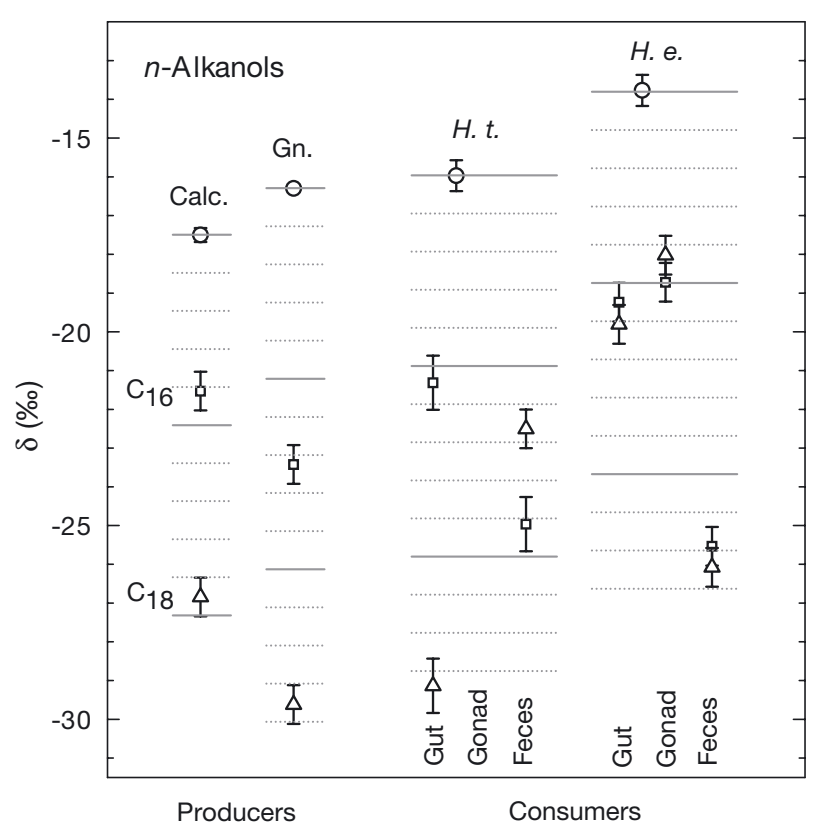

Fig. 4. Heliocidaris tuberculata (H. t.) and H. erythrogramma (H. e.) grazing on benthic algae. Isotopic compositions of $n$-alkanols displayed. $(\square, \Delta) \delta$ values for $C_{16}$ and $C_{18}$ compounds, respectively. Abbreviations as in Fig. 3 
larger depletion observed when $\mathrm{C}_{16}$ in feces from $H$. tuberculata is compared to that produced by the calcareous alga. A reversed relationship was observed for the $\mathrm{C}_{18}$ alcohol: that found in the feces was enriched in ${ }^{13} \mathrm{C}$ relative to the algal products. Possible explanations are discussed below in concert with the examination of the carboxylic acids.

In Heliocidaris tuberculata, significant concentrations of $n$-alkanols were found only in the gut tissue. Both the $\mathrm{C}_{16}$ and $\mathrm{C}_{18}$ alkanols in the gut had $\delta$ values which did not differ significantly from those in the algae. They were, therefore, probably derived from assimilation of components within the diet.

\section{Carboxylic acids}

Molecular distribution. The results of the analyses are summarized in Table 7, which shows that diverse compounds were present in the products of saponifica- tion of the lipid extract. Their possible sources include carboxylic acids that are free, as well as those bound in triglycerides, wax esters, polar lipids, and other esters. The distributions were dominated by $\mathrm{C}_{14: 0}, \mathrm{C}_{16: 0}$, and $\mathrm{C}_{18: 0}$.

Polyunsaturated compounds were rare in the macroalgae but more abundant in the biomass of the sea urchins (Table 7). Monounsaturated carboxylic acids were common in Heliocidaris erythrogramma. Carboxylic-acid distributions for the gonad and gut from $H$. tuberculata included, in addition to $\mathrm{C}_{14: 0}$ and $\mathrm{C}_{16: 0}$ significant proportions of unsaturated $\mathrm{C}_{18}$ and $\mathrm{C}_{20}$ carboxylic acids - the $\mathrm{C}_{18: 2}$ and $\mathrm{C}_{18: 1}$ carboxylic acids as well as the $\mathrm{C}_{20: 4}, \mathrm{C}_{20: 2}$, and $\mathrm{C}_{20: 1}$ compounds. Multiple isomers of the $\mathrm{C}_{18: 1}$ and $\mathrm{C}_{20: 1}$ carboxylic acids were present.

Each sample (apart from the gut) of Heliocidaris tuberculata also contained small amounts of iso and anteiso odd-carbon-number acids (Table 7), notably iso- $\mathrm{C}_{15}$ and iso- $\mathrm{C}_{17}$ acids commonly attributed to bacte-

Table 7. Heliocidaris spp. grazing on benthic algae. Relative abundance (\%) of individual carboxylic acids. Compound numbers specify total carbon numbers including methyl branch if present; $i$ and ai: iso $\left(\mathrm{CH}_{3}\right.$ branch at $\left.n-1\right)$ and anteiso $\left(\mathrm{CH}_{3}\right.$ branch at $\left.n-2\right)$

\begin{tabular}{|c|c|c|c|c|c|c|c|c|c|}
\hline \multirow[b]{2}{*}{ Index } & \multirow[b]{2}{*}{ Carboxylic acid } & \multicolumn{2}{|c|}{ Algae } & \multicolumn{3}{|c|}{ H. tuberculata } & \multicolumn{3}{|c|}{ H. erythrogramma } \\
\hline & & Calcareous & Green & Gut & Gonad & Feces & Gut & Gonad & Feces \\
\hline 1 & $12: 0$ & 0.2 & & & 0.2 & 1.0 & 0.2 & 0.3 & \\
\hline 2 & 13:0 & 0.1 & & 0.1 & & 0.9 & 0.5 & 0.5 & \\
\hline 3 & $14: 1$ & & & 0.1 & 1.1 & & & & \\
\hline 4 & $14: 0$ & 13 & 12 & 7.0 & 31 & 13 & 13 & 19 & 5.8 \\
\hline 5 & i15:0 & 0.6 & 0.7 & & 0.2 & 1.2 & 0.4 & 0.3 & 0.7 \\
\hline 6 & ai15:0 & 0.3 & 1.7 & & 0.1 & 0.9 & & & 0.5 \\
\hline 7 & $15: 0$ & 1.3 & 0.7 & 0.7 & 0.8 & 2.4 & 1.4 & 1.6 & 1.4 \\
\hline 8 & i16:0 & 0.2 & 0.4 & & & 0.2 & 0.2 & 0.2 & 0.3 \\
\hline 9 & $16: 1$ & 0.1 & 0.3 & 2.6 & 0.1 & & & & \\
\hline 10 & $16: 0$ & 70 & 56 & 19 & 25 & 50 & 37 & 37 & 53 \\
\hline 11 & $i 17: 0$ & 0.6 & 0.4 & & 0.1 & 0.3 & 1.1 & 0.8 & 0.5 \\
\hline 12 & ai17:0 & 0.4 & 0.9 & & & 0.3 & 0.6 & 0.4 & 0.4 \\
\hline 13 & $17: 0$ & 0.7 & 0.7 & 0.8 & 0.3 & 1.9 & 1.5 & 2 & 1.7 \\
\hline 14 & $18: 2$ & 0.9 & 0.2 & & 0.3 & 0.4 & 3.4 & 0.7 & 0.4 \\
\hline 15 & $18: 1$ & & & 2.6 & 3.2 & & & 0.9 & \\
\hline 16 & $18: 1$ & & & 3.1 & 4.2 & & & 1.0 & \\
\hline 17 & 18:0 & 10 & 23 & 11 & 3.1 & 22 & 20 & 17 & 33 \\
\hline 18 & 19:1 & & & 1.2 & 0.5 & & & 0.4 & \\
\hline 19 & 19:0 & 0.2 & & 0.6 & 0.1 & 0.7 & 1.6 & 1.0 & 0.3 \\
\hline 20 & $20: 4$ & & & 4.7 & 1.4 & & & & \\
\hline 21 & $20: 2$ & & & 12 & 6.0 & & 11 & 2.1 & \\
\hline 22 & $20: 1$ & & & 25 & 9.8 & & & 3.6 & \\
\hline 23 & 20:0 & 0.4 & 1.8 & 2.0 & 0.6 & 2.0 & 3.0 & 1.5 & 1.1 \\
\hline 24 & $21: 2$ & & & & & & 0.6 & & \\
\hline 25 & $21: 1$ & & & 1.6 & 0.8 & & & & \\
\hline 26 & 21:0 & & & & 0.1 & 0.4 & & & \\
\hline 27 & $22: 1$ & & & 4.5 & 4.8 & & & 3.9 & \\
\hline 28 & $22: 0$ & 0.2 & 0.9 & 0.4 & 0.1 & 1.2 & 1.1 & 0.9 & 0.3 \\
\hline 29 & $23: 1$ & & & 0.8 & 0.2 & & & 0.9 & \\
\hline 30 & 23:0 & & & & & 0.3 & & 0.9 & \\
\hline 31 & $24: 1$ & & & 0.5 & 0.1 & & & 0.8 & \\
\hline 32 & $24: 0$ & 0.1 & & 0.1 & & 0.5 & 0.7 & 0.5 & \\
\hline
\end{tabular}


rial sources (Gillan \& Johns 1986, Kaneda 1991). In the algal samples these may represent free-living organisms. In the sea urchins, they are likely to be at least partly enteric.

Villinski et al. (2002) studied the distributions of carboxylic acids in the wax-ester and triglyceride fractions of eggs from Heliocidaris erythrogramma and $H$. tuberculata. Only $\mathrm{C}_{14: 0}$ was prominent in wax esters from the eggs of $H$. erythrogramma, but the triglycerides contained approximately equal amounts of $\mathrm{C}_{14: 0}$ and $\mathrm{C}_{16: 0}$. The present analyses show, however, that total carboxylic acids from the gonad were dominated by $\mathrm{C}_{16: 0}$. Accordingly, significant quantities of this compound must derive from polar lipids in addition to the saponification of the wax esters and triglycerides. The triglyceride and wax ester fractions of $H$. tuberculata eggs were also dominated by $\mathrm{C}_{14: 0}$ and $\mathrm{C}_{16: 0}$. Therefore, most of the alkenoic acids found in $H$. tuberculata must originate from other sources, such as the polar lipids or other parts of the biomass.
Isotopic compositions. Values of $\delta$ for individual compounds are listed in Table 8. Isotopic relationships among the major carboxylic acids in specific organisms and tissues are summarized graphically in Fig. 5.

There are 3 lines of evidence that suggest that the $\mathrm{C}_{14: 0}$ acid in the urchin tissues derives largely from de novo biosynthesis: (1) it was enriched in ${ }^{13} \mathrm{C}$ by $8 \%$ relative to $\mathrm{C}_{14: 0}$ in the algae, (2) its relative abundance was substantially higher in the urchins than in the algae, and (3) in the gonads of both species, it was depleted in ${ }^{13} \mathrm{C}$ relative to biomass by a consistent amount, specifically $2 \%$ (such consistent depletions relative to biomass are characteristic of de novo products; Hayes 2001). The $\mathrm{C}_{16: 0}$ acid from urchin tissues was enriched in ${ }^{13} \mathrm{C}$ by only 3 to $5 \%$ relative to the same compound in the algae. The $\mathrm{C}_{18: 0}$ acid in the animals was not significantly enriched in ${ }^{13} \mathrm{C}$ relative to its algal counterparts. From these observations, we estimate that the $\mathrm{C}_{18: 0}$ in the urchin tissues derives mainly from the diet, that the $\mathrm{C}_{14: 0}$ in the gonadal tissue from

Table 8. Heliocidaris spp. grazing on benthic algae. Isotopic composition (\%o) of bulk samples (biomass) and carboxylic acids, $\delta^{13} \mathrm{C}$ versus VPDB. Further details as in Table 7

\begin{tabular}{|c|c|c|c|c|c|c|c|c|c|}
\hline \multirow[b]{4}{*}{ Index } & \multirow{4}{*}{$\begin{array}{l}\text { Biomass: } \\
\text { Carboxylic acid }\end{array}$} & \multicolumn{2}{|c|}{ Algae } & \multicolumn{3}{|c|}{ H. tuberculata } & \multicolumn{3}{|c|}{ H. erythrogramma } \\
\hline & & Calcareous & Green & & & & & & \\
\hline & & -17.5 & -16.3 & & -16.0 & & & -13.8 & \\
\hline & & & & Gut & Gonad & Feces & Gut & Gonad & Feces \\
\hline 1 & $12: 0$ & & & & & -16.4 & -23.3 & -17.8 & \\
\hline 2 & $13: 0$ & & & & & -19.9 & -18.0 & -18.7 & \\
\hline 3 & $14: 1$ & & & & -14.8 & & & & \\
\hline 4 & $14: 0$ & -26.2 & -25.1 & -18.5 & -17.9 & -19.4 & -18.2 & -15.8 & -22.9 \\
\hline 5 & $i 15: 0$ & -19.7 & -21.2 & & & -23.8 & -16.6 & -20.9 & -23.8 \\
\hline 6 & ai15:0 & -27.1 & -21.7 & & & -25.0 & -25.3 & & -28.0 \\
\hline 7 & $15: 0$ & -25.4 & -22.5 & -23.2 & -18.2 & -22.7 & -22.0 & -20.5 & -26.5 \\
\hline 8 & i16:0 & -25.1 & -21.7 & & & & -19.5 & -19.0 & \\
\hline 9 & $16: 1$ & -21.4 & & -15.2 & -16.0 & & & & \\
\hline 10 & $16: 0$ & -25.3 & -24.1 & -23.2 & -21.4 & & -19.5 & -19.6 & -23.8 \\
\hline 11 & $i 17: 0$ & & -19.9 & & & & & -22.6 & \\
\hline 13 & $17: 0$ & -23.8 & -22.5 & -21.9 & -15.4 & -21.1 & -21.2 & -19.9 & -25.9 \\
\hline 14 & $18: 2$ & & -25.3 & & -16.4 & & -20.6 & -17.5 & -23.2 \\
\hline 15 & $18: 1$ & & & -20.2 & -16.9 & & & -17.2 & \\
\hline 16 & $18: 1$ & & & -20.7 & -17.9 & & & -16.3 & \\
\hline 17 & $18: 0$ & -20.8 & -19.5 & -21.0 & -20.1 & -19.7 & -20.5 & -19.0 & -19.9 \\
\hline 18 & 19:1 & & & -22.9 & -19.5 & & & -19.7 & \\
\hline 19 & 19:0 & -23.3 & & -23.1 & -20.2 & -20.2 & -19.1 & -20.2 & -26.8 \\
\hline 20 & $20: 4$ & & & -22.6 & -19.8 & & & & \\
\hline 21 & $20: 2$ & -19.1 & & -19.4 & -17.3 & & -22.1 & -21.3 & \\
\hline 22 & $20: 1$ & & & -20.8 & -19.7 & & & & \\
\hline 23 & $20: 0$ & -24.0 & -22.9 & -21.6 & -24.9 & -20.2 & -20.0 & -18.5 & -21.0 \\
\hline 25 & $21: 1$ & & & -24.3 & -21.8 & & & & \\
\hline 26 & 21:0 & & & & & -21.5 & & & \\
\hline 27 & $22: 1$ & & & -22.6 & -21.9 & & & -17.9 & \\
\hline 28 & $22: 0$ & & -24.0 & -21.8 & -20.7 & & -21.8 & & -23.3 \\
\hline 29 & $23: 1$ & & & -21.5 & -25.2 & & & -17.1 & \\
\hline 30 & 23:0 & & & & -22.5 & & & -21.9 & \\
\hline 31 & $24: 1$ & & & -23.4 & -23.5 & & & -16.7 & \\
\hline 32 & $24: 0$ & -21.7 & & -21.7 & & -22.4 & -23.9 & -26.7 & \\
\hline
\end{tabular}




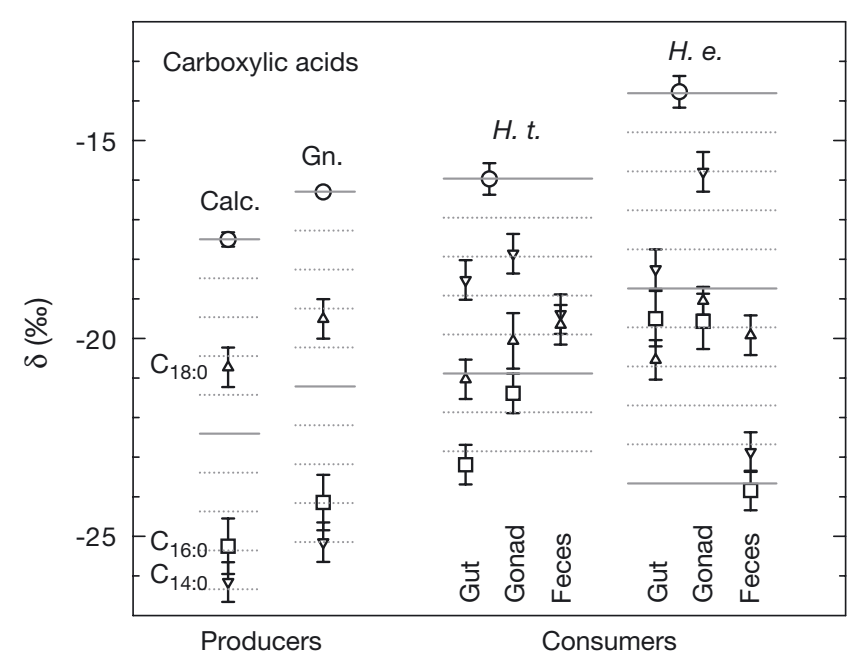

Fig. 5. Heliocidaris tuberculata (H. t.) and H. erythrogramma (H. e.) grazing on benthic algae. Isotopic compositions of major carboxylic acids. $(\Delta, \square, \nabla) \delta$ values for $C_{18: 0}, C_{16: 0}$, and $\mathrm{C}_{14: 0}$ acids, respectively. Abbreviations as in Fig. 3

each urchin derives entirely from de novo biosynthesis, and that the $\mathrm{C}_{16: 0}$ acid in the urchin tissues, and the $\mathrm{C}_{14: 0}$ in gut tissues derives from a mixture of de novo biosynthesis and assimilation of dietary carbon skeletons.

The extent of mixing can be estimated from massbalance calculations. The relevant equation is

$$
\delta_{\mathrm{o}}=f_{\mathrm{b}} \delta_{\mathrm{b}}+\left(1-f_{\mathrm{b}}\right) \delta_{\mathrm{a}}
$$

where $\delta_{0}$ is the observed isotopic composition of an acid isolated from animal tissues and $\delta_{\mathrm{b}}$ and $\delta_{\mathrm{a}}$ are the isotopic compositions of the de novo biosynthesized and assimilated components. $f_{\mathrm{b}}$ is the fractional abundance of the de novo biosynthesized component in the mixture. In this case, the value of $\delta_{\mathrm{b}}$ for each urchin species is given by the observed isotopic composition of the $\mathrm{C}_{14: 0}$ acid in gonadal tissue and the value of $\delta_{\mathrm{a}}$ is estimated from the average composition of the algal acids. Since all values of $\delta$ are known, values of $f_{\mathrm{b}}$ can be calculated. Results and uncertainties are shown in Table 9. As an example, approximately half $(47 \%)$ of the $\mathrm{C}_{16: 0}$ acid in the gonadal tissue of $H$. tuberculata derives from de novo biosynthesis, and the remainder has been assimilated from the algal diet.

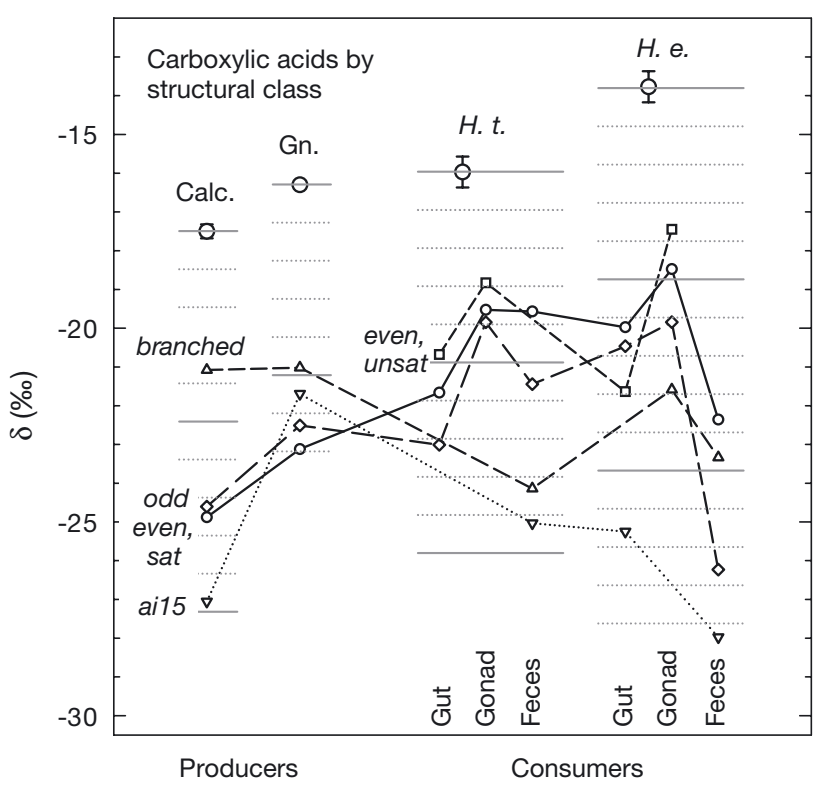

Fig. 6. Heliocidaris tuberculata (H. t.) and H. erythrogramma $(H$. e.) grazing on benthic algae. Weighted-average $\delta$ values for carboxylic acid classes. $(\Delta)$ branched: includes all iso and anteiso carbon skeletons, independent of carbon number; ( $\square$ ) even, unsat.: includes all even-carbon acids with 1 or more double bonds in alkyl chain; $(\diamond)$ odd: includes all odd-C, $n$ alkyl acids, independent of degree of saturation; ( $\bigcirc)$ even, sat.: includes all even-carbon, saturated acids. For each of these classes, a $\delta$ value was plotted only if combined relative abundances in a given sample exceeded $0.5 \%$. ( $\nabla)$ ai15: represents specifically the anteiso $\mathrm{C}_{15}$ carboxylic acid, with no concentration threshold. Abbreviations as in Fig. 3

Table 9. Heliocidaris tuberculata $(H . t$.) and H. erythrogramma (H. e.). Sources of major carboxylic acids in urchin tissues. Indicated uncertainties are $\pm 1 \mathrm{SD}$. All samples except $\mathrm{C}_{16: 0}$ in $H$. erythrogramma were analyzed in duplicate

\begin{tabular}{|c|c|c|c|c|c|}
\hline \multirow[t]{3}{*}{ Acid } & \multirow[t]{3}{*}{ Source } & \multirow{3}{*}{$\begin{array}{c}\text { Observed } \\
\text { urchin tissue } \\
\left(\delta_{0}, \% \circ\right)\end{array}$} & \multicolumn{2}{|c|}{ - Isotopic composition } & \multirow{3}{*}{$\begin{array}{l}\text { Fraction due } \\
\text { to biosynthesis } \\
\qquad\left(f_{\mathrm{b}}\right)\end{array}$} \\
\hline & & & \multicolumn{2}{|c|}{ Mixed components } & \\
\hline & & & $\begin{array}{c}\text { De novo biosynthesis } \\
\left(\delta_{\mathrm{b}}, \% \mathrm{o}\right)\end{array}$ & $\begin{array}{l}\text { Assimilated } \\
\qquad\left(\delta_{a}, \% \circ\right)\end{array}$ & \\
\hline $\mathrm{C}_{14: 0}$ & H. t. gut & $-18.5 \pm 0.5$ & $-17.9 \pm 0.5$ & $-25.5 \pm 0.5$ & $0.92 \pm 0.13$ \\
\hline $\mathrm{C}_{16: 0}$ & H.t. gut & $-23.2 \pm 0.5$ & $-17.9 \pm 0.5$ & $-24.5 \pm 0.5$ & $0.20 \pm 0.11$ \\
\hline $\mathrm{C}_{16: 0}$ & H.t. gonad & $-21.4 \pm 0.5$ & $-17.9 \pm 0.5$ & $-24.5 \pm 0.5$ & $0.47 \pm 0.12$ \\
\hline $\mathrm{C}_{14: 0}$ & H. e.gut & $-18.2 \pm 0.5$ & $-15.8 \pm 0.5$ & $-25.5 \pm 0.5$ & $0.75 \pm 0.09$ \\
\hline $\mathrm{C}_{16: 0}$ & H. e. gut & $-19.5 \pm 0.7$ & $-15.8 \pm 0.5$ & $-24.5 \pm 0.5$ & $0.57 \pm 0.11$ \\
\hline $\mathrm{C}_{16: 0}$ & H. e. gonad & $-19.6 \pm 0.7$ & $-15.8 \pm 0.5$ & $-24.5 \pm 0.5$ & $0.56 \pm 0.11$ \\
\hline
\end{tabular}


In the fecal matter, the $\mathrm{C}_{18: 0}$ and $\mathrm{C}_{16: 0}$ acids had isotopic compositions that did not differ significantly from the same compounds in the algae (Fig. 6). Accordingly, they are likely to represent unabsorbed components of the diet. The $\mathrm{C}_{14: 0}$ acid, on the other hand, was slightly (Heliocidaris erythrogramma) or markedly (H. tuberculata) enriched in ${ }^{13} \mathrm{C}$ relative to its algal counterparts. To a significant extent, therefore, it must represent loss of carbon skeletons biosynthesized by the urchins.

The isotopic compositions and relative abundances of the $\mathrm{C}_{16}$ and $\mathrm{C}_{18}$ alkanols in the feces were previously noted as problematic. Specifically, the isotopic compositions differed from those of the alkanols in the urchin tissues and in the algae, and the $\mathrm{C}_{16}$ alkanol was dominant in the feces even though it was less abundant than the $\mathrm{C}_{18}$ in all other samples. The results summarized in Table 8 show that the $\delta$ values of the highly abundant algal $\mathrm{C}_{16: 0}$ acids were closely similar to those of the fecal $\mathrm{C}_{16}$ alkanols. It appears, therefore, that a portion of the algal $\mathrm{C}_{16: 0}$ carboxylic acids is reduced to the corresponding alcohol within the urchin gut. Correspondingly, reduction of the algal $\mathrm{C}_{18: 0}$ acid will yield a product that is isotopically enriched relative to the algal $\mathrm{C}_{18}$ alkanol. Together, these processes account for the otherwise puzzling relationship in which the $\mathrm{C}_{16}$ fecal alkanols are isotopically depleted and the $\mathrm{C}_{18}$ fecal alkanols are isotopically enriched relative to the same compounds in the algae.

Weighted-average isotopic compositions of all carboxylic acids in various structural classes are summarized graphically in Fig. 6. The lines in Fig. 6 are intended only to tie together the points representing each class and do not imply relationships between the pools. Based on isotopic composition, 2 groups of acids appear. One is comprised of the branched-chain carboxylic acids; within this grouping, the anteiso $\mathrm{C}_{15}$ carboxylic acid was frequently depleted in ${ }^{13} \mathrm{C}$ relative to other branched-chain acids; for this reason, its isotopic composition is plotted separately. The second grouping combines all remaining acids, specifically the saturated and unsaturated even- $\mathrm{C}$ acids and the odd-C acids (both saturated and unsaturated). The isotopic relationship between the saturated and unsaturated even-C acids in the urchin tissues is consistent with a common source for both classes, namely de novo synthesis or, for the urchins, a combination of de novo synthesis and assimilation from the diet. The isotopic compositions of the odd-C acids indicate that they are related to the unbranched, even-C acids.

On structural grounds, the branched-chain acids are likely to be bacterial products (Gillan \& Johns 1986, Kaneda 1991). The pronounced depletion of ${ }^{13} \mathrm{C}$ in the anteiso $\mathrm{C}_{15}$ carboxylic acid indicates that it derives from a bacterium that is isotopically distinct, either because it uses an isotopically depleted substrate or because unusually large isotopic fractionations are associated with its biosynthesis of $n$-alkyl carbon skeletons. In the algal samples, the bacterial products were generally enriched in ${ }^{13} \mathrm{C}$ relative to the carboxylic acids produced by the host organism. In the urchin tissues, they were depleted. Notably, the same relationship holds for the odd-C acids, probably indicating that a significant portion of the odd-C acid pool in each sample is of bacterial origin.

\section{CONCLUSIONS}

Carbon skeletons of sterols in 2 species of Heliocidaris urchin, $H$. erythrogramma and $H$. tuberculata, derive from the urchins' diets and from de novo biosynthesis. Shorter-chain carboxylic acids $\left(\mathrm{C}_{14: 0}\right)$ are products of de novo biosynthesis, whereas the $\mathrm{C}_{18: 0}$ acid is mainly assimilated. The $\mathrm{C}_{16: 0}$ acid is derived from both processes. $H$. tuberculata synthesizes many more unsaturated carboxylic acids than $H$. erythrogramma. Many of these are found in triglycerides used as storage lipids in eggs. Branched and odd-C carboxylic acids from both organisms have $\delta$ values consistent with partial derivation from bacteria. Fatty alcohols are scarce, except in the eggs of $H$. erythrogramma, in which wax esters serve as storage lipids, in this case, they are products of de novo biosynthesis. Other alkanols found in urchin tissues have ${ }^{13} \mathrm{C}$ abundances consistent with assimilation from dietary sources.

The lipids excreted by both heterotrophs resemble those of the diet both in terms of molecular distribution and isotopic composition. In fecal matter, therefore, the characteristics of the primary producers are dominant.

Acknowledgements. We thank the Sydney Aquarium and the School of Biological Science at the University of Sydney for their generous help with facilities, and New South Wales Fisheries for providing research collecting permits. We thank H. Sowden and E. Popodi for help with collections of marine organisms. We are grateful to S. Sylva for help with extractions at Woods Hole Oceanographic Institution, and to S. Studley and J. Fong at Indiana University for technical assistance with isotopic analyses. Laboratory work was supported by NASA Exobiology grants NAG5-6660 and 9422 to J.M.H. J.T.V. was supported by an NIH Genetics training grant and an NSF grant to R.A.R.

\section{LITERATURE CITED}

Bligh EG, Dyer WJ (1959) A rapid method of total lipid extraction and purification. Can J Biochem Physiol 37:911-917

Bortolomeazzi R, De Zan M, Pizzale L, Conte LS (1999) Mass spectrometry characterization of the 5 alpha-, 7 alpha-, and beta-hydroxy derivatives of beta-sitosterol, campesterol, stigmasterol and brassicasterol. J Agric Food Chem 47:3069-3074 
Bradshaw SA, O'Hara SCM, Corner EDS, Eglinton G (1989) Assimilation of dietary sterols and faecal contribution of lipids by the marine invertebrates Neomysis integer, Scrobicularia plana and Nereis diversicolor. J Mar Biol Assoc UK 69:891-911

CoBabe EA, Ptak AJ (1999) Comparison of in situ mineralassociated lipid compositions in modern invertebrate skeletons: preliminary evidence of dietary and environmental influence. Paleobiology 25:201-211

Corner EDS (1986) Copepod faecal pellets and the vertical flux of biolipids. In: Corner EDS, O'Hara SCM (eds) The biological chemistry of marine copepods. Clarendon Press, Oxford, p 260-321

DeNiro MJ, Epstein S (1978) Influence of diet on the distribution of carbon isotopes in animals. Geochim Cosmochim Acta 42:495-506

Des Marais DJ, Mitchell JM, Meinschein WG, Hayes JM (1980) The carbon isotope biogeochemistry of the individual hydrocarbons in bat guano and the ecology of the insectivorous bats in the region of Carlsbad, New Mexico. Geochim Cosmochim Acta 44:2075-2086

Emlet RB, Hoegh-Guldberg O (1997) Effects of egg size on postlarval performance: experimental evidence from a sea urchin. Evolution 51:141-152

Fry B (1988) Food web structure on Georges Bank from stable C, N, and S isotopic compositions. Limnol Oceanogr 33: $1182-1190$

Gillan FT, Johns RB (1986) Chemical markers for marine bacteria: fatty acids and pigments. In: Johns RB (ed) Biological markers in the sedimentary record. Elsevier, Amsterdam, p 291-309

Grice K, Klein-Breteler WCM, Schouten S, Grossi V, de Leeuw JW, Sinninghe-Damste JS (1998) Effects of zooplankton herbivory on biomarker proxy records. Paleoceanography 13:686-693

Hayes JM (2001) Fractionation of carbon and hydrogen isotopes in biosynthetic processes. In: Valley JW, Cole DR (eds) Stable isotope geochemistry. Rev Mineral Geochem 43:225-278

Hayes JM, Freeman KH, Popp BN, Hoham CH (1989) Compound-specific isotopic analyses: a novel tool for reconstruction of ancient biogeochemical processes. Org Geochem 16:1115-1128

Hoegh-Guldberg O, Emlet RB (1997) Energy use during the development of a lecithotrophic and a planktotrophic echinoid. Biol Bull (Woods Hole) 192:27-40

Itoh T, Tani H, Fukushima K, Tamura T, Matsumoto T (1982) Structure-retention relationship of sterols and triterpene alcohols in gas chromatography on a glass capillary column. J Chromatogr 234:65-76

Kaneda T (1991) Iso- and anteiso-fatty acids in bacteria: biosynthesis, function, and taxonomic significance. Microbiol Rev 55:288-302

Lawrence JM, Byrne M (1994) Allocation of resources to body components in Heliocidaris erythrogramma and Heliocidaris tuberculata (Echinodermata: Echinoidea). Zool Sci 11:133-137

Leckrone KJ, Hayes JM (1997) Efficiency and temperature dependence of water removal by membrane dryers. Anal

Editorial responsibility: Otto Kinne (Editor), Oldendorf/Luhe, Germany
Chem 69:911-918

Michener RH, Schell DM (1994) Stable isotope ratios as tracers in marine aquatic food webs. In: Lajtha, Michener $\mathrm{R}$ (eds) Stable isotopes in ecology and environmental science. Blackwell Scientific, Oxford, p 138-157

Pancost RD, Freeman KH, Wakeham SG (1999) Controls on the carbon-isotope compositions of compounds in Peru surface waters. Org Geochem 30:319-340

Patterson GW (1971) Relation between structure and retention time of sterols in gas chromatography. Anal Chem 43: 1165-1170

Prahl FG, Eglinton G, Corner EDS, O'Hara SCM, Forsberg TEV (1984) Changes in plant lipids during passage through the gut of Calanus. J Mar Biol Assoc UK 64: 317-334

Raff R (1992) Direct-developing sea urchins and the evolutionary reorganization of early development. BioEssays 14:211-218

Smith D (1984) Biogeochemistry of lipids in recent organicrich marine sediments. PhD thesis, University of Bristol, UK

Soudant P, Marty Y, Moal J, Robert R, Quere C, Coz JRL, Samain JF (1996) Effect of food fatty acid and sterol quality on Pecten maximus gonad composition and reproduction process. Aquaculture 143:361-378

Stott AW, Davies E, Evershed RP, Tuross N (1997) Monitoring the routing of dietary and biosynthesised lipids through compound-specific stable isotope $\left(\delta^{13} \mathrm{C}\right)$ measurements at natural abundance. Naturwissenschaften 84:82-86

Tsushima M, Byrne M, Amemiya S, Matsuno T (1995) Comparative biochemical studies of carotenoids in sea urchins. III. Relationship between developmental mode and carotenoids in the Australian echinoids Heliocidaris erythrogramma and $H$. tuberculata and a comparison with Japanese species. Comp Biochem Physiol B 110:719-723

van der Zanden MJ, Rasmussen JB (2001) Variation in $\delta^{15} \mathrm{~N}$ and $\delta^{13} \mathrm{C}$ trophic fractionation: implications for aquatic food web studies. Limnol Oceanogr 46:2061-2066

Veron B, Billard C, Dauguet JC, Hartmann MA (1996) Sterol composition of Phaeodactylum tricornutum as influenced by growth temperature and light spectral quality. Lipids 31:989-994

Villinski JT, Villinski JC, Byrne M, Raff RA (2002) Convergent maternal provisioning and developmental mode in echinoderms. Evolution 56:1764-1775

Volkman JK, Corner EDS, Eglinton G (1980) Transformations of biolipids in the marine food web and in underlying bottom sediments. Colloq INSERM-CNRS 293:185-197

Voogt PA, Bissumbhar B, Idzinga TM, Wynne HJ, Jansen M (1993) Effects of cadmium on sterol composition in the aboral body-wall of the sea star Asteria rubens L. Comp Biochem Physiol C 104:415-421.

Wakeham SG (1995) Lipid biomarkers for heterotrophic alteration of suspended particulate organic matter in oxygenated and anoxic water columns of the ocean. Deep-Sea Res I 42:1749-1771

Yoshii K, Melnik NG, Timoshkin OA, Bondarenko NA, Anoshko PN (1999) Stable isotope analyses of the pelagic food web in Lake Baikal. Limnol Oceanogr 44:502-511

Submitted: April 16, 2003; Accepted: February 10, 2004 Proofs received from author(s): June 18, 2004 